\title{
Research on Credit Risk of Corporate Bond Based on Principal Component Analysis and Cluster Analysis
}

\section{Jingwei Liu Tianyong Luo}

School of Finance, Guizhou University of Finance and Economics, Guiyang Guizhou 550025, China

\begin{abstract}
In this paper, through the collection of corporate bond market data to conduct empirical research, Constructing 12 Index Systems, Using the principal component analysis method to extract the five principal component indicators, On the basis of principal component analysis, two kinds of clustering analysis were used to classify the data into two categories, And finally draw the corresponding conclusion: The profitability and solvency of the industry is the key to distinguish the credit rating of the enterprise. It is the main factor to distinguish between the two types of corporate bonds and the focus of the investors' investment.
\end{abstract}

Keywords

Corporate bonds, Credit risk, Profitability, Solvency

\section{基于主成分分析和聚类分析的企业债券 信用风险研究}

\author{
刘婧玮 罗天勇 \\ 贵州财经大学金融学院, 贵阳 550025, 中国
}

摘要：企业债券可以使企业减少融资成本，分散风险，合理配置资源。然而，企业债券也存 在着风险, 在企业债券所面临的风险中最主要的风险即为信用风险。本文通过收集我国企业 债券市场上的数据来进行实证研究, 构建 12 个指标体系, 使用主成分分析法抽取出五个主 成分指标，在主成分分析的基础上使用两部聚类分析法将数据分为两类，得出相应结论：企 业的盈利能力与偿债能力是区分企业信用评级的关键, 是区分两类企业债券的主要因素、也 是投资者投资时所需着重关注的重点。

关键词：企业债券；信用风险；盈利能力；偿债能力

长久以来，中国的金融体系主要

1. 引言 依靠银行间接贷款的方式来进行融 资，然而这种以银行间接融资为主的 
方式导致了一些不良后果，例如过度 货币化，抬高整个社会的融资成本和 使得经济具有高杜杆性等。而与银行 间接融资方式不同的是债券，债券作 为债券发行者获取融资的一种直接形 式, 与银行贷款间接融资和股权融资 相比, 债券融资的方法有很多优点, 且与国外债券市场已经发展完善的发 达国家相比, 中国的债券市场由于发 展不完善反而存在着很大的发展空 间。

企业通过发行企业债券的方式来 获取融资是企业融资的一种常见而又 重要的融资方法与融资手段, 企业债 券拥有很多优点, 最突出的优点为企 业债券的流动性强、约束性强、以及 成本较低。

从我国的实际来看, 多方面的因 素互相作用使得中国的企业债券市场 发展缓慢, 其中的一个主要原因就是 信息的不对称而造成的信用风险。信 息的不对称导致了投资者不了解发债 企业的真实信息与经营状况，为了获 得企业的信息投资者需要付出较高的 信息收集成本以及面临着信用风险所 带来的损失。信用风险已经成为了我 们企业债券市场所面临的一个主要风 险。

基于以上背景, 本文利用主成分 分析法与两步聚类分析法对我国企业 债券进行实证研究, 旨在通过本文的 研究, 以更好的帮助投资者在进行投 资时减少因信用风险所带来的损失, 从而促进我国企业债券市场与金融市 场的又好又快发展。

\section{2. 文献综述}

Ericsson, Jacobs \& Oviedo(2005)建 立了一个研究企业信用风险的多元回 归模型, 该模型通过对发行企业债券 的公司的财务杜杆、无风险利率以及 股票波动和风险溢价的关系进行研
究, 模型中以风险溢价作为因变量其 余作为自变量。由模型得出当财务杜 杆的比例增加了百分之一时企业的信 用风险溢价就会提高百分之五至百分 之十。Madan \&Xiaoling Zhang(2006)使 用了一个公司债券信用风险的结构模 型, 该模型由短期利率和公司的财务 困境两个因素来驱动。通过这个研究 得出结论, 公司的短期利率变动对债 券利差的影响是最显著的。

林毅夫和李永军(2001) 指出中国 的企业在运用外部融资的方法进行融 资时通常会存在着许多信息不对称的 情况, 且这些情况尚未发现良好的解 决方法。周宏（2010）指出目前国内 国外对影响企业债券的信用风险的因 素的研究基本上从大的宏观环境的不 确定性和企业的内部价值以及信息的 不对称性这三个方面进行研究。其 次, 在关于信用风险的理解上, 何运 强和方兆本 (2003) 等大部分的学者 把企业债券的信用风险理解为企业债 券发生违约的风险。违约风险指的是 发行企业债券的企业由于各种原因而 使得该企业不能如约按期偿还本金和 利息而给投资该企业债券的投资者带 来损失的风险。陈燕玲（2008）等一 部分学者认为应用债务人或是交易双 方中某一方违约或是履约能力产生问 题而带来损失的风险来定义信用风 险。

\section{3. 企业债券市场发展现状}

\section{1. 企业债券市场的债券发行量增加、 市场规模不断扩大}

随着金融经济的不断发展, 企业 债券市场在金融市场的发展中显得越 发重要。随着我国对企业债券市场的 重视, 我国企业债券市场的发行数量 与交易数量在不断地增加, 企业债券 市场的规模不断扩大，2002 年企业债 
券实际发行的总量是 325 亿元, 随着 企业债券市场的不断发展，到了 2016 年企业债券的发行总量增加到了 5925.7 亿元, 与 2002 年 325 亿元的发 行量相比，2016 年企业债券发行量扩 大了近 18.23 倍, 并且还有不断增长的 趋势。

\section{2. 企业债券市场的增信方式、发行主 体、发行内容越来越具有多元化 的特点}

首先从增信方面来看，从 2009 年 以来，企业债券的发行中体现出了多 种多样的增信方式, 包括应收账款质 押、上地使用权质押、股权质押、第 三方担保、偿债基金等。发行主体方 面, 根据相关的各项法律法规的规 定, 我国当前的企业债券市场上除了 中央与地方企业可以发行债券之外, 非国有企业、民营企业以及能够符合 发行企业债券的其他中小企业也可以 成为企业债券发行的主体。发行内容 方面, 只要企业能够符合法定的程序 条件和实体条件要求, 企业就可以发 行企业债券和其他各种债券品种。

\section{4. 企业债券市场的信用风险}

通常意义上我们可以了解到, 信 用风险由两部分来组成, 其中第一部 分是违约风险, 第二部分是指信用价 差所带来的风险。

通过上述概念以及已有研究我们 可以知道，信用风险制约着我国企业 债券市场的发展, 成为了债券市场的 最大制约因素。它之所以成为了债券 市场的最大制约因素，首要的原因就 是我国信用评级制度的不健全以及不 完善, 投资者获取企业信息困难, 企 业债券与银行的贷款和股票具有不同 的特点。当发行企业债券的企业在经 营中发生了失败, 到了约定的日期没 有能力按照约定偿还企业的债务, 当
发生这种现象时首先遭受损失的就是 投资市场上广大的中小投资者，并且 在我国目前的债券环境下, 企业债券 带来的损失比商业银行的贷款更难通 过法律途径去解决, 这不仅不利于广 大投资者, 也不利于我国债券市场的 发展, 甚至会对整个社会的经济发展 造成不良影响。因此, 必须正确的看 待、妥善解决好该问题。

\section{5. 实证研究}

\section{1. 指标的选取}

在阅读一系列参考文献的基础 上, 肖彦、刘君（2013）基于主成分 分析法与聚类分析的上市公司财务综 合评价一以农业上市公司为例选定了 指标。指标表如下表。

表 1: 信用风险评价指标表

\begin{tabular}{|c|c|c|}
\hline 一级指标 & 二级指标 & 计算公式 \\
\hline \multirow{4}{*}{ 偿债能力 } & 流动比率 & 流动资产 / 流动负债 \\
\hline & 速动比率 & （流动资产-存货） / 流动负债 \\
\hline & 资产负债率 & 负债总额 / 资产总额 \\
\hline & 利息偿还倍数 & (利润总额+财务费用)/ 财务费用 \\
\hline \multirow{4}{*}{ 营运能力 } & 存货周转率 & 销售成本 / 平均存货 \\
\hline & 应收账款周转率 & 营业收入/ 平均应收账款余额 \\
\hline & 流动资产周转率 & 销售收入 / 平均流动资产余额 \\
\hline & 总资产周转率 & 销售收入/总资产 \\
\hline \multirow{4}{*}{ 盈利能力 } & 销售净利率 & 净利润 / 销售收入净额 \\
\hline & 资产报酬率 & 净利润 / 平均资产总额 \\
\hline & 营业利润率 & 净利润/营业收入 \\
\hline & 净资产收益率 & 净利润/ 净资产 \\
\hline
\end{tabular}

上述指标体系中资产负债率、速 动比率和流动比率为适度指标, 其余 都为正指标, 因而要对其进行正向 化。使用 $\mathrm{x}^{\prime}=1 /|\mathrm{x}-\mathrm{A}|$ 的方法来对指标进 行正向化, 其中 $\mathrm{A}$ 为 $\mathrm{X}$ 的理论最优 值, 如流动比率一般为 2 、速动比率为 1、资产负债率为 $50 \%$ 。

\section{2. 软件分析}

\section{3.1 主成分分析法}

我们将从国泰安数据库获取到的 108 组数据导入 SPSS 软件中, 运用 SPSS22. 0 对企业债券 12 个指标进行运 算 (系统已经自动标准化), 得出的 
相关系数矩阵的特征值和各主成分的 贡献率如下表:

表 2: 解释的总方差表

\begin{tabular}{|c|c|c|c|c|c|c|c|c|c|}
\hline \multirow[b]{2}{*}{ 成分。 } & \multicolumn{3}{|c|}{ 初姮特征值 } & \multicolumn{3}{|c|}{ 提取平方和载入 } & \multicolumn{3}{|c|}{ 茠转平方和载入 } \\
\hline & 合ite & 方差的最 & 累积虹 & 合计. & 方差旳㫛。 & 累积 8 . & 合计。 & 方差的瑚 & 赫积 \\
\hline 1 & 3.548 & 29.564 . & 29.564 & 3.548 & 29.564. & 29.564 & 3.219 & 26.825 & 26.825 \\
\hline 2 & 2.079 & 17.326 . & 46.890 & 2.079 & 17.326. & 46.890 & 2.319 & 19.326 . & 46.151 \\
\hline 3 & 1.232 & 10.266 . & 57.156 & 1.232 & 10.266 . & 57.156 & 1.221 & 10.176 & 56.327 \\
\hline 4 & 1.105 & 9.206 & 66.362 & 1.105 & 9.206. & 66.362 & 1.161 & 9.677 & 66.004 \\
\hline 5 & 1.009 & 8.412 & 74.774 & 1.009 & 8.412 & 74.774 & 1.052 & 8.770 & 74.774 \\
\hline 6 & .908 & 7.565 & 82.338 & & & & & & \\
\hline ? & .893 & 7.443 & 89.782 & & & & & & \\
\hline 8 & .685 & 5.708. & 95.490 . & & & & & & \\
\hline 9 & .380 & 3.170 & 98.660. & & & & & & \\
\hline 10 & .160 & 1.332 & 99.991. & & & & & & \\
\hline 11 & .001 & . 009. & 100.000 & & & & & & \\
\hline 12 & $1.451 E-16$ & $-1.210 E-15$. & 100.000. & & & & & & \\
\hline
\end{tabular}

由表 2 可知, 初始特征值大于 1 可以选取为主成分，上表中前 5 个主 成分累积贡献率为 $74.774 \%$ ，较好地解 释了样本数据中包含的信息, 可以使 用 5 个主成分因子来替代之前所选取 的 12 个指标, 这五个主成分因子分别 记为 F1、F2、F3、F4、F5。

碎石图特征值的大小代表了主成 分的方差贡献率大小和重要性程度。 从下图中我们可以看出, 从第五个因 子开始后面的曲线开始变得较为平 缓，特征值不断下降，因此可以初步 确定抽取前 5 个因子作为主要因子。

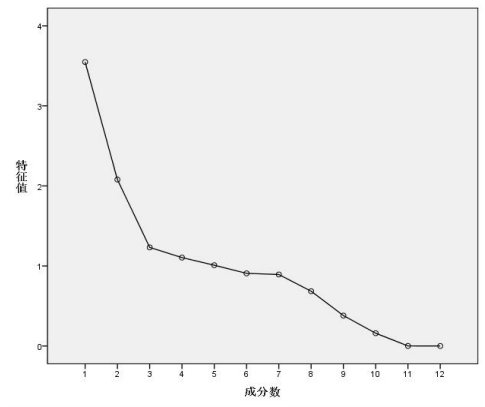

图 1：碎石图
表 3: 旋转成本矩阵表

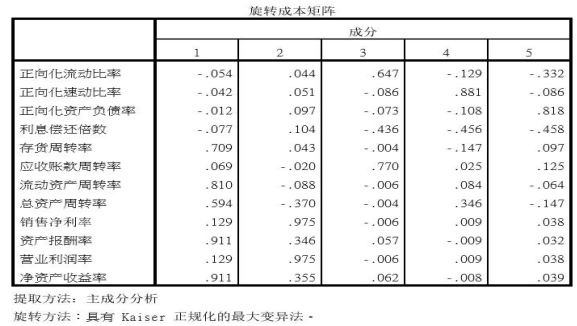

由上表可知, 主因子 F1 与净资产 收益率、存货周转率、流动资产周转 率、资产报酬率、总资产周转率等指 标具有较大的相关性, 其方差贡献率 为 $29.564 \%$, 故 F1 可以定义为盈利营 运因子。主因子 F2 与营业利润率、销 售净利率、资产报酬率、净资产收益 率都有较大的相关性, 其方差贡献率 为 $17.326 \%$, 其中有三个指标均属于盈 利能力中偏向利润方面, 故 F2 定义为 盈利利润因子。主因子 F3 与正向化速 动比率指标具有较大的相关性, 其方 差贡献率为 $10.266 \%$, 故 F3 定义为偿 债因子。主因子 F4 与正向化速动比 率、总资产周转率等指标具有较大的 相关性, 其方差贡献率为 9.206\%, 故 F4 定义为偿债营运因子。主因子 F5 与 正向化资产负债率、利息偿还倍数、 正向化流动比率等指标具有较大的相 关性, 其方差贡献率为 $8.412 \%$, 故 F5 定义为偿债综合因子。

表 4: 成分得分系数矩阵表

\begin{tabular}{|c|c|c|c|c|c|}
\hline & \multicolumn{5}{|c|}{ 成分 } \\
\hline & 1 & 2 & 3 & 4 & 5 \\
\hline 正向化流动比率 & -.040 & .050 & .551 & -.123 & -.336 \\
\hline 正向化橦动比率 & -.065 & .098 & -.100 & .788 & -.106 \\
\hline 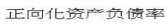 & -.005 & -.023 & -.075 & -.105 & .785 \\
\hline 利息佯还倍数 & .008 & .049 & -.327 & -.361 & -.427 \\
\hline 存值周转率 & .240 & -.063 & -.028 & -169 & .093 \\
\hline 应收账政周转率 & -.007 & -.012 & .629 & -.015 & .101 \\
\hline 流动凌厂周转率 & .273 & -.105 & -.040 & .023 & -.059 \\
\hline 总染产周转率 & .212 & -.191 & -.042 & .248 & -.124 \\
\hline 销售净利率 & -.047 & .440 & .002 & .072 & -.035 \\
\hline 报酬率 & .270 & .075 & .016 & -.037 & .004 \\
\hline 营业利洞率 & -.047 & .440 & .002 & .072 & -.035 \\
\hline 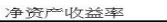 & .269 & .079 & .019 & -.036 & .009 \\
\hline
\end{tabular}

见上表中每个指标的得分可以得 出最终的主因子得分方程. 通过得分方 程计算的得分可以对主因子进行进一 
步的分析解释. 由上表可以列出 5 个主 成分因子的得分方程:

$\mathrm{F} 1=-0.040 \mathrm{X} 1-0.065 \mathrm{X} 2-0.005 \mathrm{X} 3+0.0$ $08 \mathrm{X} 4+0.240 \times 5-0.007 \times 6+0.273 \times 7+0.21$ $2 \mathrm{X} 8-0.047 \mathrm{X} 9+0.270 \mathrm{X} 10-0.047 \mathrm{X} 11+0.26$ 9X12

$\mathrm{F} 2=0.050 \times 1+0.098 \times 2-0.023 \times 3+0.0$ 49X4-0.063X5-0.012X6-0.105X7-0.191 $\mathrm{X} 8+0.440 \mathrm{X} 9+0.075 \mathrm{X} 10+0.440 \mathrm{X} 11+0.07$ 9X12

$\mathrm{F} 3=0.551 \times 1-0.100 \times 2-0.075 \times 3-0.32$ $7 \mathrm{X} 4-0.028 \times 5+0.629 \times 6-0.040 \times 7-0.042 \mathrm{X}$ $8+0.002 \times 9+0.016 \times 10+0.002 \times 11+0.019$ $\mathrm{X} 12$

$\mathrm{F} 4=-0.123 \mathrm{X} 1+0.788 \mathrm{X} 2-0.105 \times 3-0.3$ 61X4-0.169X5-0.015X6+0.023X7+0.248 X8+0.072X9-0.037X10+0.072X11-0.036 $\mathrm{X} 12$

$\mathrm{F} 5=-0.336 \times 1-0.106 \times 2+0.785 \times 3-0.4$ $27 \mathrm{X} 4+0.093 \mathrm{X} 5+0.101 \mathrm{X} 6-0.059 \times 7-0.124$ X8-0.035X9+0.004X10-0.035X11+0.009 $\mathrm{X} 12$

其中, $\mathrm{X} 1 、 \mathrm{X} 2 、 \mathrm{X} 3 、 \mathrm{X} 4 、 \mathrm{X} 5$ 、 $\mathrm{X} 6 、 \mathrm{X} 7 、 \mathrm{X} 8 、 \mathrm{X} 9 、 \mathrm{X} 10 、 \mathrm{X} 11 、 \mathrm{X} 12$ 为原始变量标准化后的变量。

根据 SPSS22.0 所计算出来的原始 数据各因子的得分，通过该得分乘以 各因子相应的方差的算术平方根，可 以得到对应主成分的得分。综合得到 的 5 个新变量的主成分得分, 以公因 子的方差贡献率为权数与该主成分得 分相乘可得出企业债券信用风险评价 的综合值 $F$ ，其公式如下:

$\mathrm{F}=0.39538 \mathrm{~F} 1+0.23171 \mathrm{~F} 2+0.13729 \mathrm{~F}$ $3+0.12312 \mathrm{~F} 4+0.11250 \mathrm{~F} 5$

根据评价函数可以对我国企业债 券信用风险进行综合评分, 并对其排 名。下图为前 20 名综合得分及排名:

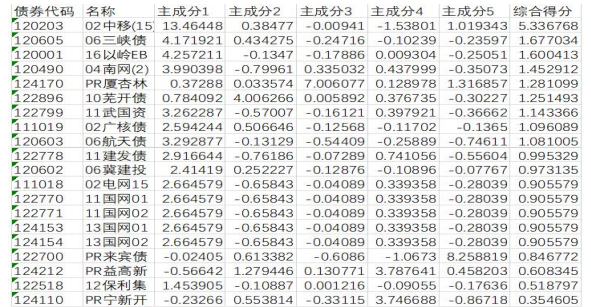

图 2: 综合得分排名图
同时根据上述企业债券信用风险 评价模型可以得出:

模型中 F1、F2 的系数较大, 即盈 利指标对企业债券的影响较大，根据 模型得出的 $\mathrm{F}$ 值中最大值与最小值的 极差为 7.35 , 显示了我国企业债券市 场上企业债券间主要财务指标差异 大，信用风险存在可能性大。

\section{3.2 两步聚类分析}

在上述因子分析的基础上，使用 软件进行两部聚类分析, 获得结果如 下:

表 5: 自动聚类分析表

\begin{tabular}{|c|c|c|c|c|}
\hline 整类数且 & 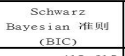 & 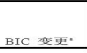 & 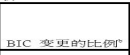 & 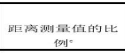 \\
\hline & $\begin{array}{l}\begin{array}{l}418.61 \\
332.797\end{array} \\
33.79\end{array}$ & & & \\
\hline & $\begin{array}{l}322.849 \\
334.720\end{array}$ & -10.948 & .129 & $\begin{array}{l}2.652 \\
1.652\end{array}$ \\
\hline & (351.562 & 16.855 & -199 & $\begin{array}{l}1.167 \\
1.340\end{array}$ \\
\hline & $\begin{array}{l}\begin{array}{l}376.020 \\
410.369\end{array} \\
40.9\end{array}$ & $\begin{array}{l}24.458 \\
34.349\end{array}$ & $\begin{array}{l}.288 \\
.05 \\
.05\end{array}$ & $\begin{array}{l}1.7 \\
1.0 \\
1.0\end{array}$ \\
\hline 8 & $\begin{array}{l}\begin{array}{l}444.925 \\
481.234\end{array} \\
4\end{array}$ & $\begin{array}{l}\begin{array}{l}34.556 \\
36.308\end{array} \\
36.03\end{array}$ & $\begin{array}{l}.407 \\
.248 \\
\end{array}$ & $\begin{array}{l}1.167 \\
1.112\end{array}$ \\
\hline & $\begin{array}{l}518.603 \\
55863\end{array}$ & 37.370 & $\begin{array}{ll}4+1 \\
472\end{array}$ & 1.389 \\
\hline 12 & $\begin{array}{l}538.618 \\
598.919\end{array}$ & $\begin{array}{l}40.013 \\
40.301\end{array}$ & 年725 & $\begin{array}{l}1.044 \\
1.273 \\
1.273\end{array}$ \\
\hline 13 & $\begin{array}{l}640.619 \\
683.783 \\
6.93\end{array}$ & $\begin{array}{l}41.700 \\
43.164\end{array}$ & $\begin{array}{l}.492 \\
.500 \\
\end{array}$ & 1.0 \\
\hline & & & & \\
\hline
\end{tabular}

根据表 5 所展示的数据我们可以 了解到, 当 BIC 值变更值最小为84.818 且距离测量值的比例最大为 2.279 时为最优聚类数目, 因此我们可 以确定最优聚类数目为 2 .

表 6: 聚类分配表

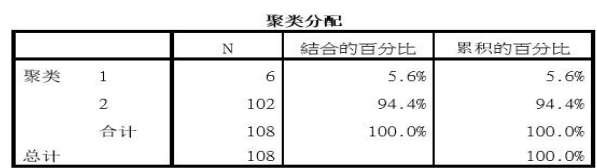

从该表我们可以看出本次聚类一 共分为了两类, 在 108 组样本数据 中, 第一类有 6 个样本, 占总样本数 据的 $5.6 \%$ ，第二类有 102 个样本，占 总样本数据的 $94.4 \%$ 。

表 7: 质心表

\begin{tabular}{|c|c|c|c|c|}
\hline & \multicolumn{3}{|c|}{ 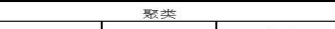 } \\
\hline & & 1 & & 合计 \\
\hline FAC1_1 & $\begin{array}{l}\text { 平均数 } \\
\text { 标准差 }\end{array}$ & $\begin{array}{r}.9944567 \\
3.07965861\end{array}$ & $\begin{array}{r}.0584971 \\
.72641677\end{array}$ & $\begin{array}{r}.0000004 \\
.99999999 \\
.\end{array}$ \\
\hline FAC2_1 & 平均数 & .2613517 & -.0153737 & -. .0000001 \\
\hline FAC3_1 & $\begin{array}{l}\text { 平垉 } \\
\text { 标准 }\end{array}$ & $\begin{array}{r}2.0708083 \\
3.60478837\end{array}$ & $\begin{array}{r}.1218121 \\
.38259759\end{array}$ & $\begin{array}{l}.0000002 \\
.99999975\end{array}$ \\
\hline FAC4_1 & 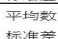 & $\begin{array}{r}-.7428950 \\
8.825446\end{array}$ & $\begin{array}{l}.0436998 \\
.0956912\end{array}$ & $\begin{array}{l}.0000001 \\
.0999922\end{array}$ \\
\hline FAC5_1 & 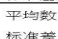 & $\begin{array}{l}417 \\
577\end{array}$ & $\begin{array}{r}-.0753145 \\
.47726262\end{array}$ & $\begin{array}{l}-.0000003 \\
1.00000016\end{array}$ \\
\hline
\end{tabular}


由以上表 7 质心表我们可以研究 探索两个聚类之间的差别, 从对质心 表的研究中我们可以看出, 第一类的 债券从盈利营运因子、盈利利润因 子、偿债因子、偿债营运因子、偿债 综合因子这五个方面来看标准差都远 远大于第二类债券, 数据波动大, 第 一类债券只有 6 个, 对其进行分析后 发现信用评级机构对其信用的评级多 为 $\mathrm{AA}$ 级债券, 只有一个 02 中移 (15)

(债券代码：120203) 为 AAA 级债 券, 因此我们可以知道, 对于企业债 券再说盈利能力与偿债能力十分重 要, 投资者在选择企业债券时要注重 对企业盈亏能力与偿债能力的分析。

\section{6. 结论}

本文使用了主成分分析法以及两 部聚类分析法进行实证分析, 将 12 个 指标通过主成分分析法构建为 5 个主 成分因子，然后构建企业债券信用风 险综合评价模型, 从该模型的系数中 可以看出指出盈利能力对企业债券的 重要性。

在主成分分析法的基础上又使用 了两部聚类分析的方法, 根据聚类结 果, 我们可以将企业债券分为两类, 其中第一类企业债券从五个主成分因 子方面着手, 标准差均大于第二类企 业债券, 数据波动较大, 且第一类企 业债券基本上数据 AA 级债券。

根据本文实证得出的结果, 投资 者在投资企业债券时, 要注重对发债 企业的盈利能力以及偿债能力着重考 察, 一个企业盈利能力越强, 企业在 经营过程中赚取利润的能力就越强, 就越能为投资者带来收益; 企业偿债 能力是企业能否生存和健康发展的关 键, 企业的偿债能力越强, 购买该企 业的债券多可能遭受的损失可能性就 越小。
在投资者投资企业债券的过程由 于信息不对称等各种各样的因素可能 为企业债券的交易带来信用风险, 信 用风险是制约我国企业债券市场发展 的主要因素之一, 企业债券信用风险 的产生不但不利于广大的投资者, 也 不利于我国企业债券的发展, 更严重 的信用风险会对我国整个经济社会的 发展带来不良影响。投资者们在篮选 投资企业时一定要注重对企业盈利能 力与偿债能力的衡量, 最大程度上减 少信用风险所带来的损失，以实现投 资者与企业双赢的局面。

\section{参考文献}

[1] Ericsson J, Jacobs K, Oviedo R. The Determinants of Credit Default Swap Premia[J]. Journal of Financial \& Qu antitative Analysis, 2009, 44(1):109-1 32.

[2] Madan D B, Bakshi G, Zhang F X. U nderstanding the Role of Recovery in Default Risk Models: Empirical Com parisons and Implied Recovery Rates [J]. Finance \& Economics Discussion, 2001.

[3] 林毅夫, 李永军. 中小金融机构发展 与中小企业融资 $[\mathrm{J}]$. 经济研究, 2001(1):10-18.

[4] 周宏,林晚发,李国平等. 信息不对称 与企业债券信用风险估价一一基于 2008-2011 年中国企业债券数据 [J]. 会计研究, 2012(12):36-42.

[5] 何运强, 方兆本. 债券信用评级与信 用风险 $[\mathrm{J}]$. 管理科学, 2003,16(2):4550.

[6] 刘小坤.企业债券:信用风险与市场 监管研究[D].复旦大学,2005.

[7] 肖彦,刘君.基于主成分分析法与聚 类分析的上市公司财务综合评价一 一以农业上市公司为例 $[\mathrm{J}]$. 财会通 讯,2013(5):37-39. 